\title{
Colestipol Hydrochloride
}

National Cancer Institute

\section{Source}

National Cancer Institute. Colestipol Hydrochloride. NCI Thesaurus. Code C28938.

A hydrochloride salt form of colestipol, a positively charged, non-digestible, triamine and epoxypropane copolymer anion-exchange resin that binds to bile acids in the intestine to form an insoluble complex, which is excreted in the feces. 